\title{
Genetic and biochemical identification of a novel single-stranded DNA-binding complex in Haloferax volcanii
}

\author{
Amy Stroud ${ }^{1}$, Susan Liddell ${ }^{2}$ and Thorsten Allers ${ }^{1}$ * \\ 1 School of Biology, Queen's Medical Centre, University of Nottingham, Nottingham, UK \\ ${ }^{2}$ Division of Animal Sciences, University of Nottingham, Loughborough, UK
}

Edited by:

Zvi Kelman, University of Maryland, USA

Reviewed by:

Jocelyne DiRuggiero, The Johns

Hopkins University, USA

Stuart MacNeill, University of St

Andrews, UK

*Correspondence:

Thorsten Allers, School of Biology, Queen's Medical Centre, University of Nottingham, Nottingham NG7 2UH, UK.

e-mail: thorsten.allers@

nottingham.ac.uk
Single-stranded DNA (ssDNA)-binding proteins play an essential role in DNA replication and repair. They use oligonucleotide/oligosaccharide-binding (OB)-folds, a five-stranded $\beta$-sheet coiled into a closed barrel, to bind to ssDNA thereby protecting and stabilizing the DNA. In eukaryotes the ssDNA-binding protein (SSB) is known as replication protein A (RPA) and consists of three distinct subunits that function as a heterotrimer. The bacterial homolog is termed SSB and functions as a homotetramer. In the archaeon Haloferax volcanii there are three genes encoding homologs of RPA. Two of the rpa genes (rpa1 and rpa3) exist in operons with a novel gene specific to Euryarchaeota; this gene encodes a protein that we have termed RPA-associated protein (rpap). The rpap genes encode proteins belonging to COG3390 group and feature OB-folds, suggesting that they might cooperate with RPA in binding to ssDNA. Our genetic analysis showed that rpa1 and rpa3 deletion mutants have differing phenotypes; only $\triangle r p a 3$ strains are hypersensitive to DNA damaging agents. Deletion of the rpa3-associated gene rpap3 led to similar levels of DNA damage sensitivity, as did deletion of the rpa3 operon, suggesting that RPA3 and RPAP3 function in the same pathway. Protein pull-downs involving recombinant hexahistidine-tagged RPAs showed that RPA3 co-purifies with RPAP3, and RPA1 co-purifies with RPAP1. This indicates that the RPAs interact only with their respective associated proteins; this was corroborated by the inability to construct rpa1 rpap3 and rpa3 rpap1 double mutants. This is the first report investigating the individual function of the archaeal COG3390 RPA-associated proteins (RPAPs). We have shown genetically and biochemically that the RPAPs interact with their respective RPAs, and have uncovered a novel single-stranded DNA-binding complex that is unique to Euryarchaeota.

Keywords: archaea, Haloferax volcanii, RPA single-strand DNA-binding protein, COG3390 RPA-associated protein, DNA repair, protein overexpression, Cdc48d

\section{INTRODUCTION}

Genomic DNA must be unwound in order to be replicated or repaired, leaving it vulnerable to nuclease and chemical attack as well as open to the possibility of forming secondary structures. Binding of the single-stranded DNA (ssDNA)-binding proteins (SSB) RPA and SSB prevents any of these events from occurring (Lu et al., 2009). The SSB is denominated SSB in bacteria and replication protein A (RPA) in eukaryotes; they bind to ssDNA with high affinity and to dsDNA and RNA with low affinity (Wobbe et al., 1987; Wold et al., 1989; Kim et al., 1992). They play a vital organizational role in the central genome maintenance of the cell, providing docking platforms for a wide range of enzymes to gain access to genomic substrates ( $\mathrm{Lu}$ and Keck, 2008). The bacteriophage T4 gene 32 monomer was the first SSB to be identified (Alberts and Frey, 1970). RPA was first identified as an essential protein for DNA replication in the eukaryotic simian virus (SV40; Wobbe et al., 1987) by stimulating the T antigenmediated unwinding of the SV40 origin of replication (Kenny et al., 1989). RPA and SSB have now been established as essential proteins for DNA metabolism including DNA replication, recombination, and repair in all domains of life (Wobbe et al., 1987; Heyer et al., 1990; Coverley et al., 1991, 1992; Moore et al., 1991; Wold, 1997). The basic architecture of RPA and SSB is based on the oligonucleotide/oligosaccharide-binding (OB)-fold, a fivestranded $\beta$-sheet coiled into a closed barrel, but the number of OB-folds present varies from species to species (Bochkarev and Bochkareva, 2004; Fanning et al., 2006).

Unlike in bacteria and eukaryotes, the architecture of SSBs present in archaea is not uniform. There is wide diversity of SSBs in the two main archaeal phyla, Euryarchaea, and Crenarchaea. Crenarchaea possess SSBs similar to those of bacteria, consisting of a single subunit with one OB-fold and an acidic C-terminus tail (Rolfsmeier and Haseltine, 2010). Euryarchaea have RPA-like proteins that show homology with the eukaryotic RPA, but from species to species the architecture of euryarchaeal RPAs varies dramatically from a single polypeptide RPA to an RPA made up of several subunits. Each of these RPAs can contain up to four OB-folds as well as a zinc finger motif (Rolfsmeier and Haseltine, 2010). 
Pyrococcus furiosus RPA consists of three subunits RPA41, 14, and 32, denominated RPA1, 2, and 3, respectively, which form a heterotrimer as seen in eukaryotes. Strand exchange and immunoprecipitation assays have shown that $P$. furiosus heterotrimeric RPA stimulates strand exchange, and interacts with the clamp loader RFC and both DNA polymerases B and D (Komori and Ishino, 2001). The heterotrimeric complex seen in P. furiosus is also found in $P$. abyssi and P. horikoshii. However, in other archaeal species the rpa genes have undergone lineage-specific duplications, resulting in differing numbers of SSBs with diverse structures. Unlike the RPA complex found in Pyrococcus spp., or eukaryotic RPA, these do not form trimeric complexes (Robbins et al., 2004).

Methanosarcina acetivorans possesses three RPA subunits, MacRPA1, 2, and 3, which are unlikely to form a heterotrimeric complex as seen in P. furiosus and in eukaryotes. MacRPA1 contains four DNA-binding domains (DBD) containing OB-folds, MacRPA 2 and 3 both have two OB-fold containing DBDs. Each of the three MacRPAs can function as SSBs, and are able to stimulate primer extension by M. acetivorans DNA polymerase BI (Robbins et al., 2004, 2005). This demonstrates an element of redundancy between the three MacRPAs, and suggests that the heterotrimeric RPA structure observed in P. furiosus is the exception and not the rule. Lin et al. (2008) suggest that intramolecular recombination between RPA homologs may have led to the diversity of RPAs found in euryarchaea, which can function in different pathways or cellular processes.

A similar pattern of lineage-specific gene duplication is seen with the archaeal MCM helicase, where the number and type of MCM subunits that make up the hexameric helicase differ between archaeal species. The genes encoding the MCM subunits fall into distinct phylogenetic clades, but these do not correspond to specific subunits of eukaryotic MCM. Instead they have arisen through lineage-specific gene family expansion (Chia et al., 2010). Such gene duplication might allow different archaeal species to refine the structure and function of MCM (and potentially RPA) for differing conditions and specialized roles.

Sulfolobus solfataricus has a bacterial-like SSB consisting of a small $20 \mathrm{kDa}$ peptide containing one OB-fold and an acidic Cterminus tail (Haseltine and Kowalczykowski, 2002; Rolfsmeier and Haseltine, 2010). The S. solfataricus SSB quaternary structure is similar to that of $E$. coli SSB, however the primary structure of the OB-fold shows greater homology to that of the eukaryotic RPA70 DNA-binding domain B (DBDB). This suggests that crenarchaeal SSBs may be structurally similar to bacterial SSB but at a protein sequence level show homology to the eukaryotic RPA (Haseltine and Kowalczykowski, 2002; Kerr et al., 2003). In S. solfataricus there is an absence of DNA damage recognition proteins such as homologs of XPA or XPC to initiate NER. The ability of S. solfataricus SSB to specifically bind and melt damaged duplex DNA in vitro suggests SSB may play a role in the identification and binding of damaged DNA, followed by the subsequent recruitment of NER repair proteins (Cubeddu and White, 2005).

Haloferax volcanii encodes three RPA genes rpa1, rpa2, and rpa3 (Hartman et al., 2010). Recent studies have shown RPA2 to be essential while RPA1 and RPA3 are not (Skowyra and MacNeill, 2012). Note that these authors used the nomenclature $r p a A 1, A 2$, $B 1, B 2, B 3$, and $C$ to refer to rpa3, rpap3, rpa1, rpap1, rpe, and rpa2, respectively, while we have chosen to maintain the official nomenclature as described in Table 4 of the $H$. volcanii genome paper (Hartman et al., 2010). Both rpal and rpa3 are in operons with other genes; rpal is in an operon with genes encoding an OB-fold containing protein (hereby designated RPA-associated protein or RPAP) and a calcineurin-like phosphoesterase, while only one OB-fold rpa-associated protein (rpap) gene is present in the rpa3 operon (Figure 1). The presence of an rpap gene in the same operon as rpa can be found in other euryarchaeota, including Halobacterium marismortui, Halobacterium salinarum, and Natronomonas pharaonis, as well as in M. mazei and M. barkeri. The rpap gene has been assigned to the cluster of orthologous groups (COG) 3390 (Berthon et al., 2008).

To examine if RPA1 and 3, as well as RPAP1 and RPAP3 play a role in DNA repair, as is true for both the bacterial SSB and eukaryotic RPA, DNA damage assays were performed using the single and operon deletion mutants. Cells with deletions of the rpa1 and rpa3 operons had previously been examined by Skowyra and MacNeill (2012). However, this is the first report investigating the individual function of the archaeal COG3390 RPAP. We show genetically and biochemically that the RPAPs interact with their respective RPAs, and have thereby uncovered a novel SSB complex that is unique to Euryarchaeota.

\section{MATERIALS AND METHODS}

All chemicals were from Sigma and restriction enzymes from New England Biolabs, unless stated otherwise. Standard molecular techniques were used (Sambrook and Russell, 2001).

\section{STRAINS AND PLASMIDS}

Haloferax volcanii strains (Table 1) were grown at $45^{\circ} \mathrm{C}$ on complete (Hv-YPC), casamino acids (Hv-Ca), or minimal (Hv-Min) agar, or in Hv-YPC or Hv-Ca broth as described previously. Isolation of genomic and plasmid DNA, as well as transformation of $H$. volcanii were carried out as described previously (Allers et al., 2004).

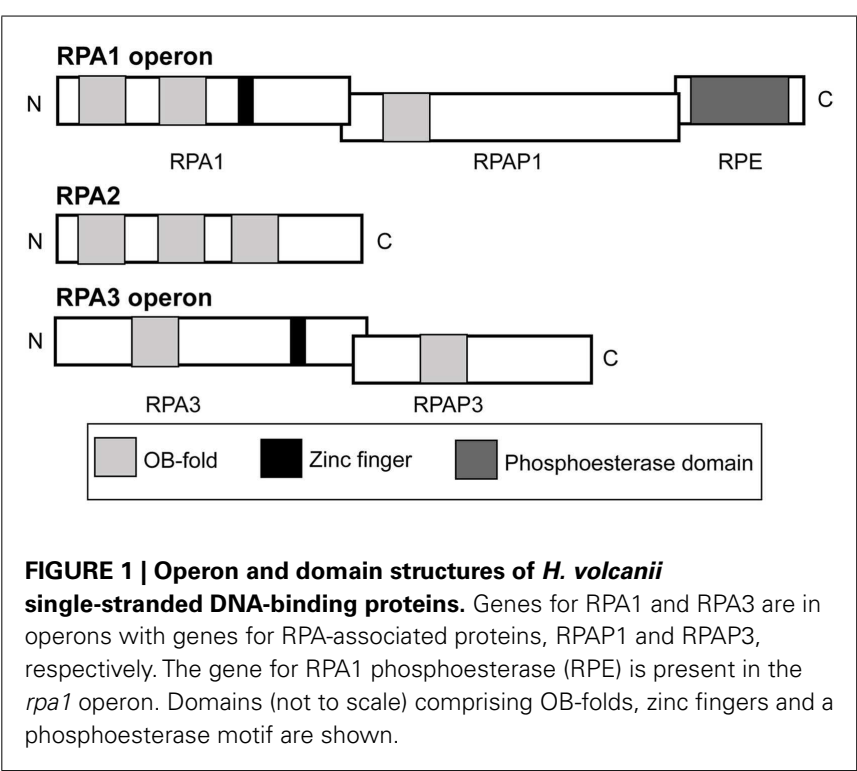


Table 1 | Haloferax volcanii strains.

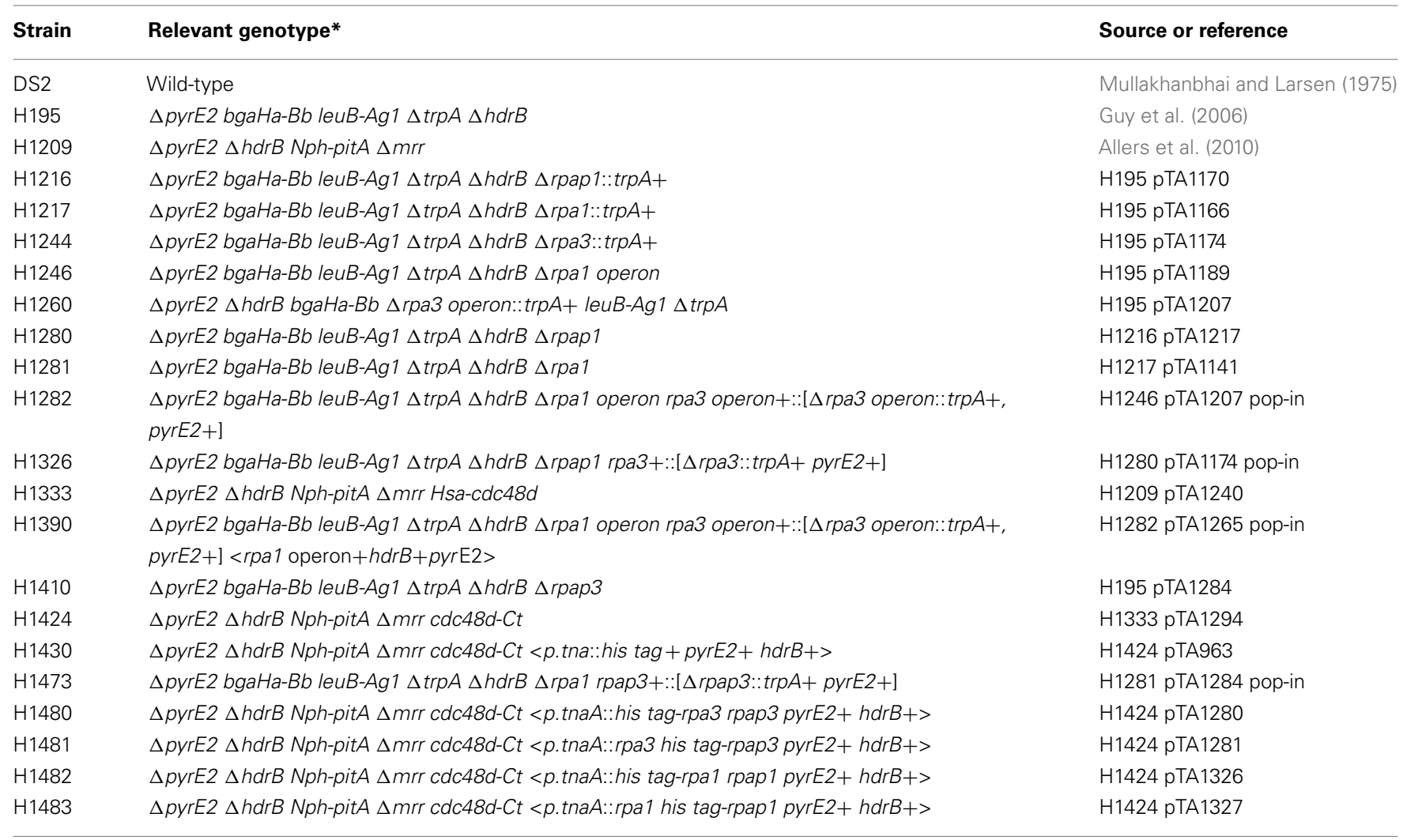

${ }^{*}$ Genes shown within <> are present on an episomal plasmid, genes shown within [] are present on an integrated plasmid (pop-in).

\section{CONSTRUCTION OF MUTANT STRAINS}

Deletion mutants were constructed as described previously (Allers et al., 2004). Plasmids for gene deletion are shown in Table 2, and were generated by PCR using oligonucleotides shown in Table 3. Template DNA for the PCRs was isolated from genomic DNA.

\section{CONSTRUCTION OF PROTEIN OVEREXPRESSION STRAINS}

Protein overexpression strains were constructed by transformation with episomal overexpression plasmids as described previously (Allers et al., 2010). Plasmids for protein expression are shown in Table 2, and were generated by PCR using oligonucleotides shown in Table 3. Template DNA for the PCRs was isolated from genomic DNA.

\section{UV IRRADIATION ASSAYS}

UV irradiation assays were carried out as described previously (Delmas et al., 2009).

\section{MITOMYCIN C ASSAYS}

Mitomycin C (MMC) assays were carried out as described previously (Lestini et al., 2010).

\section{PROTEIN OVEREXPRESSION AND PURIFICATION}

Protein overexpression was carried out as described previously (Allers et al., 2010) with the following amendments: cultures were incubated at $45^{\circ} \mathrm{C}$ overnight to an $\mathrm{OD}_{650}$ of 0.5 , when protein expression was induced by adding $3 \mathrm{mM}$ Trp to the culture followed by incubation at $45^{\circ} \mathrm{C}$, with shaking for a further $1 \mathrm{~h}$ until $\mathrm{OD}_{650} \approx 0.7$.

\section{PROTEIN PRECIPITATION}

Deoxycholate was added to $0.015 \%$, vortexed, and incubated for $10 \mathrm{~min}$ at room temperature. Trichloroacetic acid was added to $7.2 \%$ and incubated at room temperature for $5 \mathrm{~min}$. Samples were centrifuged at $14,000 \times g$ at room temperature for $8 \mathrm{~min}$. Supernatant was removed and precipitated protein resuspended in $15 \mu \mathrm{l}$ resuspension buffer (330 mM Tris- $\mathrm{HCl}$ pH 7.2, 2.6\% SDS, $17 \mathrm{mM}$ $\mathrm{NaOH}, 5 \%$ glycerol, $0.25 \mathrm{mg} / \mathrm{ml}$ bromophenol blue). Samples were heated for $10 \mathrm{~min}$ at $94^{\circ} \mathrm{C}$ and cooled on ice before loading onto an SDS-PAGE gel.

\section{MASS SPECTROMETRY}

Mass spectrometry of excised protein bands was carried out as described previously (Allers et al., 2010). Details of protein identification are given in the Table A1 in Appendix.

\section{RESULTS}

\section{RPA3 BUT NOT RPA1 FUNCTIONS IN DNA REPAIR}

In eukaryotes, specifically Saccharomyces cerevisiae, all three RPA subunits have been shown to be essential for cell survival (Brill and Stillman, 1991). Work by Skowyra and MacNeill (2012) has shown that $H$. volcanii rpa2 is essential, which is in agreement with our fruitless attempts to delete rpa2 (data not shown). To examine if the other rpa genes of $H$. volcanii are also essential, 
Table 2 | Plasmids.

Plasmid

\section{Relevant properties}

Standard cloning vector

pBluescript II SK+

pTA131

pTA409

pTA884

pTA898

pTA937

pTA963

PTA1141

pTA1142

pTA1166

pTA1170

pTA1174

pTA1180

pTA1189

pTA1196

pTA1207

pTA1217

pTA1218

pTA1222

pTA1223

pTA1224

pTA1240

pTA1265

pTA1280

pTA1281

pTA1282

pTA1284

pTA1288

pTA1294

pTA1326

pTA1327 pTA131 Ndel site

Ndel site rpap1 (Ndel compatible)

pTA1180

rpap3 at Ndel site
Integrative vector based on pBluescript II, with pyrE2 marker

Shuttle vector containing ampicillin, pyrE2 and $h d r B$ markers, and pHV1/4 replication origin

pBluescript II with $H$. volcanii 5,038-bp EcoRI/Notl genomic fragment containing rpa3 operon

pBluescript II with $H$. volcanii 7,335-bp EcoRI/NotI genomic fragment containing rpa2

pBluescript II with $H$. volcanii 8,565-bp BspEl genomic fragment containing rpa1 operon

Overexpression vector with 6xHis-tag, pyrE2 and hdrB markers, and pHV2 origin

pTA131 containing rpa1 deletion construct inserted at Kpnl and Xbal sites, contains an internal Ndel site

pTA131 containing rpa3 deletion construct inserted at $E c o R I$ and Kpnl sites, contains an internal Ndel site rpa1 deletion construct pTA1141 with trpA marker, amplified from pTA298 introducing Ndel restriction sites to insert at internal Ndel restriction site in pTA1141

Deletion construct of rpap1 containing trpA marker from pTA298 inserted at EcoRI and Kpnl sites in

rpa3 deletion construct containing trpA marker from pTA1166 inserted at Ndel restriction site

pTA131 with cdc48d deletion construct

pTA131 with rpa1 operon deletion construct inserted at restriction sites Xbal and EcoRI with an internal

rpa3 operon deletion construct, using Ndel/EcoRI downstream fragment from pTA1282 (rpap3 deletion

construct) inserted at $\mathrm{Ndel} / \mathrm{EcoRI}$ sites in PTA1142 (rpa3 deletion construct), to replace the downstream fragment of the rpa3 deletion construct

Deletion construct of rpa3 operon pTA1196 with insertion of the trpA marker from pTA1166 at internal

RPAP1 deletion construct pTA1170 with upstream and trpA fragment replaced with the upstream

fragment amplified from pTA937 by PCR, to introduce compatible Sphl sites, generating

non-trpA-marked deletion construct

pTA963 with rpa3 inserted downstream of His-tag. Asel inserted after rpa3 stop codon to allow insertion of His-tagged rpa3 upstream of His-tagged rpap3 (Asel is Ndel compatible)

pTA963 with rpa1 N-terminally His-tagged, has an Asel site downstream of rpa1 to allow insertion of

pTA963 overexpression vector with rpap1 N-terminally His-tagged inserted at Psil and BamHI sites.

rpap1 was amplified by PCR from pTA937 introducing $B s p H I$ and BamHI sites

pTA963 with rpap3 $\mathrm{N}$-terminally His-tagged inserted at Psil and EcoRI sites. RPAP3 was amplified by

PCR from pTA884 introducing $B s p H I$ and $E c o R I$ sites

Gene replacement construct with insertion of $896 \mathrm{bp} \mathrm{Hsa-cdc48d} \mathrm{gene} \mathrm{(amplified} \mathrm{from} \mathrm{H}$. salinarum

DNA) between upstream and downstream flanking regions of $\mathrm{H}$. volcanii $\mathrm{cdc} 48 \mathrm{~d}$ deletion construct

pTA409 with insertion of rpa1 operon from pTA937 at EcoRV site

pTA1218 with rpap3 amplified from pTA884 by PCR and inserted at BstEll and EcoRI sites after the

$\mathrm{N}$-terminally His-tagged rpa3, maintaining reading frame

pTA1224 with rpa3 amplified from pTA884 by PCR and inserted upstream of N-terminally His-tagged

rpap3 deletion construct with upstream and downstream regions amplified from genomic clone pTA884,

introducing external $K p n l$ and $E c o R I$ sites, used to ligate into pTA131, and internal Ndel site

rpap3 deletion construct pTA1282 with trpA marker digested from pTA1166 using Ndel and inserted at

Ndel site in pTA1282, generating trpA-marked rpap3 deletion construct

pBluescript II with $H$. volcanii 3,299-bp Sall/BspHI genomic fragment containing cdc48d gene

pTA131 with 2,247 bp Hvo-cdc48d-Ct gene replacement construct amplified from pTA1288: 1,797 bp

EcoRI-Nhel fragment with C-terminally truncated cdc48d plus upstream region, ligated to $485 \mathrm{bp}$

Nhel-Kpnl fragment with downstream region of $c d c 48 d$, inserted at EcoRI and Kpnl sites

pTA1222 with rpap1, amplified from pTA937 introducing BstEll and BamHI sites, and inserted

downstream of His-tagged rpa1 at BstEll and BamHI sites

pTA1223 with rpa1 inserted upstream of His-tagged rpap1 at Ndel site. rpa1 was amplified from pTA937

introducing Ndel and Asel (Ndel compatible) sites
Source or reference

Stratagene
Allers et al. (2004)
Delmas et al. (2009)
This study
This study
This study
Allers et al. (2010)
This study
This study
This study

This study

This study

Allers et al. (2010)

This study

This study

This study

This study

This study

This study

This study

This study

This study

This study

This study

This study

This study

This study

This study

This study

This study

This study 
Table 3 | Oligonucleotides.

\begin{tabular}{|c|c|c|c|}
\hline Oligonucleotide & Sequence $\left(5^{\prime}-3^{\prime}\right)$ & Relevant properties & $\begin{array}{l}\text { Use (plasmid } \\
\text { generated) }\end{array}$ \\
\hline Rpa1CF DS & GTTCGAGGTACCGTTCGGGGAGC & $\Delta r p a 1$ external downstream primer, Kpnl site & pTA1141 \\
\hline Rpa1 CR US & TACTACGTCTAGACGGACCTGTTCG & $\Delta r p a 1$ external upstream primer, $X$ bal site & pTA1141 \\
\hline Rpa1 CF US & GGTCGAGTTCCATATGGTCGGGATTCGCC & $\Delta r p a 1$ internal upstream primer, Ndel site & pTA1141 \\
\hline Rpa3Kpnl F & GCCGGTGGTACCACAGCCTC & $\Delta r p a 3$ external upstream primer, $K p n l$ site & pTA1142 \\
\hline Rpa3EcoRIR & GACGGTGGAATTCGGCCGTCG & $\Delta r p a 3$ external downstream primer, EcoRI site & pTA1142 \\
\hline Rpa3Ndel FC & GCGAGGTCGATGCATATGAGTTCCAACG & $\Delta r p a 3$ internal downstream primer, Ndel site & pTA1142 \\
\hline trpANdelF & СTCTGCACATATGTCGCTCGAAGACGC & $\operatorname{trpA}$ forward primer containing Ndel site & pTA1166 \\
\hline trpANdelR & TGCATGCCATATGCGTTATGTGCG & $\operatorname{trpA}$ reverse primer containing $\mathrm{Ndel}$ & pTA1166 \\
\hline RPAP11 kpnlus & CCGCGAGTGGTACCGCAAGCCCG & $\Delta r p a p 1$ external upstream primer, Kpnl site & pTA1170 \\
\hline RPAP11nsilus & CGACGACCGGCGATGCATTCATGCGCGC & $\Delta r p a p 1$ internal upstream primer, Nsil site & pTA1170 \\
\hline Rpa1CR US & TACTACGTCTAGACGGACCTGTTCG & $\Delta r p a 1$ operon external upstream primer, Xbal site & pTA1189 \\
\hline RPEndel R DS & CTACCGGAACATATGACTCGGGTCG & $\Delta r p a 1$ operon internal downstream primer, Ndel site & pTA1189 \\
\hline Rpa1ndel F2 & GTTGGACCCATATGTCGAACGACG & $\Delta r p a 1$ operon internal upstream primer, Ndel site & pTA1189 \\
\hline RPAP11Sphl US & GCGATTTCCCGCATGCCGACGACCG & $\Delta r p a p 1$ internal upstream primer, Sphl site & pTA1217 \\
\hline RPAP11 kpnl us & CCGCGAGTGGTACCGCAAGCCCG & $\Delta r p a p 1$ external upstream primer, Kpnl site & pTA1217 \\
\hline Rpa3BspHI F & AGGTAGATCATGACTGATTTGC & rpa3 forward primer, BspHI site & pTA1218 \\
\hline Rpa3 RAsel & CGAGTGGGGAATTCGTTGGAATTAATTTACATC & rpa3 reverse primer, Asel site & pTA1218 \\
\hline Rpa1F Ncol & CCCGACTCCATGGAACTCGACC & rpa1 forward primer, Ncol site & pTA1222 \\
\hline Rpa1Asel/EcoRl & $\begin{array}{l}\text { CGGCGGCGAATTCGCGGTAGGCGATTAATCGCGTGC } \\
\text { pTA1327 }\end{array}$ & rpa1 reverse primer, Asel and EcoRI sites & pTA1222 \\
\hline RPAP1F BspHI & GGTGCGCTCATGAGCGCCTCG & rpap1 forward primer, $B s p H I$ site & pTA1223 \\
\hline HsaCdc48R & CTGACAGATCTCGCAGTCACAGC & Reverse primer for $\mathrm{Hsa}-\mathrm{cdc} 48 \mathrm{~d}, \mathrm{Bg}$ III site & $\begin{array}{l}\text { pTA1240, Probe } \\
\text { Figure 5B }\end{array}$ \\
\hline Rpa3BstEll & GATGCGCGGTGACCTCGTGG & rpap3 forward primer, native BstEll site & pTA1280 \\
\hline Rpa3Ndel & CGAGGTAGCATATGACTGATTTGCG & rpa3 forward primer, Ndel site & pTA1281 \\
\hline RPAP3 gitF & CTCCCAATGGGTACCAAGGTGGAGGC & $\Delta r p a p 3$ internal upstream primer, Ndel site & pTA1282 \\
\hline RPAP3 gitR & TCGTTGGACATATGTTACATCGACCTCGC & $\Delta r p a p 3$ external upstream primer, Kpnl site & pTA1282 \\
\hline RPAP3 F DS & CTCGCTGAATTCGGTGGGTGC & $\Delta r p a p 3$ external downstream primer, EcoRI site & pTA1282 \\
\hline RPAP3 R DS & CTGAGCGCATATGCGGGCGTCTCG & $\Delta r p a p 3$ internal downstream primer, Ndel site & pTA1282 \\
\hline cdc48dUF & ACGGGTACCCACGTTGCTGG & Hvo-cdc48d external upstream primer, Kpnl site & pTA1294 \\
\hline cdc48dDR & GCCGAATTCGAGCCGAGGTGG & Hvo-cdc48d external downstream primer, EcoRI site & pTA1294 \\
\hline cdc48d-CtrR & CGGCGCGCTAGCCGGACCGGTTACGC & $\begin{array}{l}\text { Internal reverse primer to generate C-terminally trun- } \\
\text { cated } H v o-c d c 48 d \text {, Nhel site at } c d c 48 d \text { stop codon }\end{array}$ & pTA1294 \\
\hline cdc48d-CtrF & CTGTGGTGCTAGCCGTCGTCCGACCCCG & $\begin{array}{l}\text { Internal forward primer to generate C-terminal trun- } \\
\text { cated } H \text { vo-cdc } 48 d \text {, Nhel site at } c d c 48 d \text { stop codon }\end{array}$ & pTA1294 \\
\hline cdc48dSeqF & GGAAAAAGGGGCAGATGGTG & $\begin{array}{l}\text { Forward primer to downstream flanking region of Hvo- } \\
c d c 48 d\end{array}$ & PCR Figure 5C \\
\hline cdc48dHvSeqR & CGACGACATCTCGCTGATTCG & Reverse primer to $H v o-c d c 48 d$ gene & PCR Figure $\mathbf{5 C}$ \\
\hline cdc48dHsalSeqR & GGTCAACACGCTGCTGAAGTCC & Reverse primer to $\mathrm{Hsa}-\mathrm{cdc} 48 \mathrm{~d}$ gene & PCR Figure $\mathbf{5 C}$ \\
\hline Rpa1BstEII & CCGGCACGGTGACCGCCATCC & rpap1 forward primer, native BstEll site & pTA1326 \\
\hline Rpa1Ndel & CCCGACCATATGGAACTCGACC & rpa1 forward primer, Ndel site & pTA1327 \\
\hline
\end{tabular}


genomic deletions of rpal and rpa3 were generated using the counter selective pop-in/pop-out method (Allers et al., 2004). To generate the deletion constructs by PCR, rpal and rpa3 operons were first isolated from wild-type (WT) $H$. volcanii using native $B s p \mathrm{EI}$ and EcoRI/Not I restriction sites, respectively, to generate genomic libraries. These were then screened for the presence of the rpa1 and rpa3 operons, individually, using colony hybridization. The isolated plasmids, pTA937 (rpa1 operon) and pTA884 (rpa3 operon) were confirmed by DNA sequencing. Deletion constructs for rpal and rpa3 were designed to avoid polar effects on the expression of the downstream rpap genes by maintaining the reading frame. Genomic deletions of both rpal and rpa3 (trpAmarked) were successful, generating strains H1217 and H1244, respectively (Figures 2 and 3, respectively). The ability to delete both rpa1 and rpa3 with relative ease, but not rpa2, indicates that the cellular requirement for each RPA is not equal, making it unlikely that they function collectively.
Both eukaryotic and bacterial SSB are involved in DNA repair. To examine if $H$. volcanii RPA1 and RPA3 function in DNA repair, the effects of DNA damage on cell survival of H1217 and H1244 were examined. UV irradiation results in the formation of cyclobutane pyrimidine dimers and 6-4 pyrimidinepyrimidone dimer photoproducts, as well as ssDNA nicks that indirectly generate double-stranded DNA breaks (DSBs). The latter require repair by homologous recombination (HR) or single-strand DNA annealing (Fousteri and Mullenders, 2008; Rouillon and White, 2011). MMC is a chemotherapeutic agent that reacts with DNA generating covalent interstrand crosslinks, requiring removal by nucleotide excision repair (NER) and HR (Tomasz et al., 1987). The $\Delta r p a 1$ mutant H1217 was no more sensitive than the WT to UV and MMC-induced DNA damage, however the $\Delta$ rpa3 mutant H1244 exhibited moderate sensitivity to both UV and MMC-induced DNA damage (Figure 4).

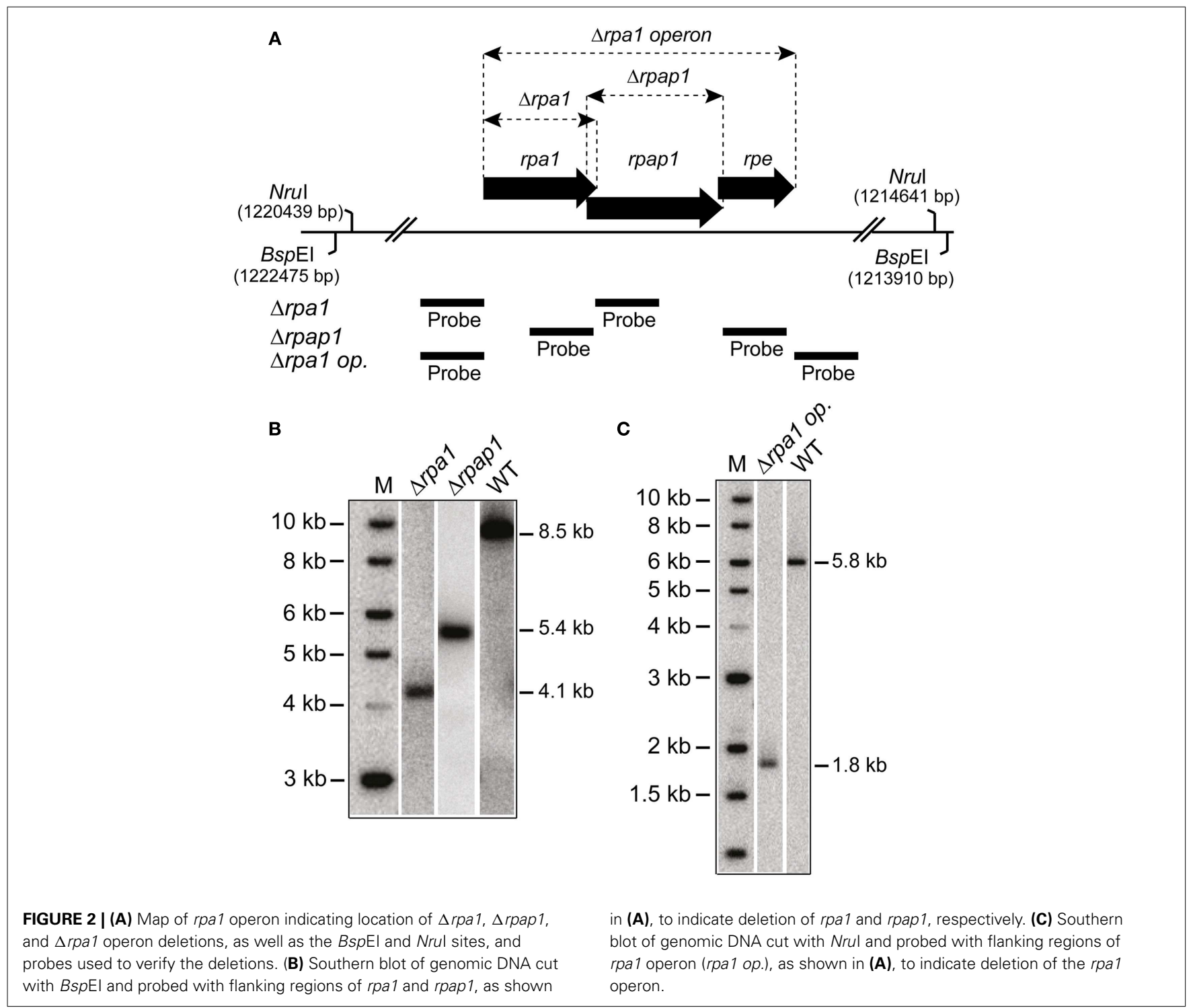




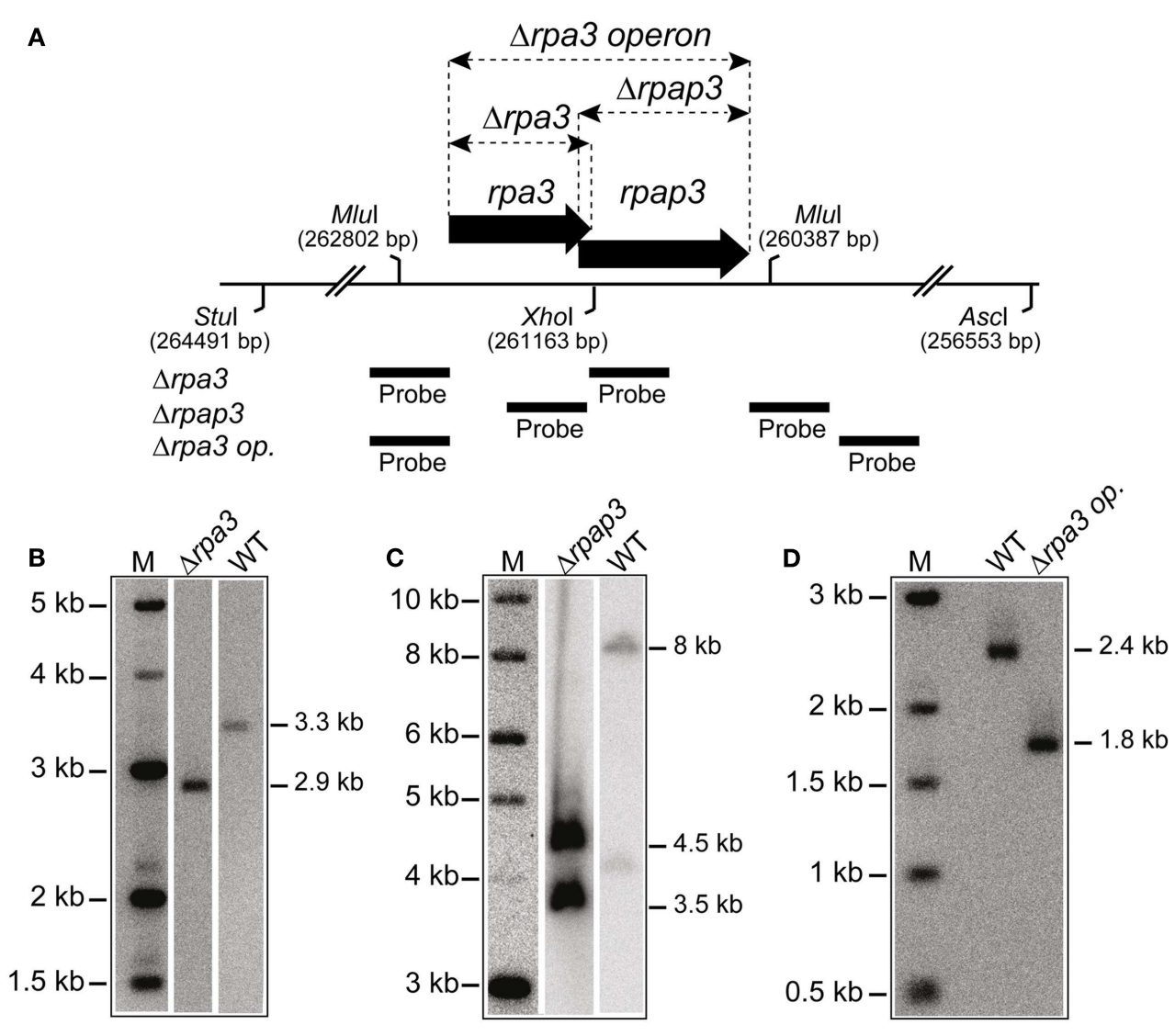

FIGURE 3 | (A) Map of rpa3 operon indicating location of $\Delta r p a 3, \Delta r p a p 3$, and $\Delta$ rpa3 operon deletions, as well as the Ascl, Mlul, Stul, and Xhol sites and probes used to verify the deletions. (B) Southern blot of genomic DNA cut with Stul and Xhol, and probed with flanking regions of rpa3, as shown in Figure 2A, to indicate deletion of rpa3. (C) Southern blot of genomic
DNA cut with Ascl and Stul, and probed with flanking regions of rpap3, as shown in Figure 2A, to indicate deletion of the rpap3. (D) Southern blot of genomic DNA cut with Mlul and probed with flanking regions of rpa3 operon (rpa3 op.), as shown in Figure 2A, to indicate deletion of the rpa3 operon.

\section{RPAP3 BUT NOT RPAP1 FUNCTIONS IN DNA REPAIR}

Analysis of predicted protein domains indicates that RPA1 and RPA3 both possess zinc finger domains, and that RPA1 has three OB-folds compared to the single OB-fold present in RPA3 (Figure 1). Both COG3390 RPAPs RPAP1 and RPAP3 possess a single OB-fold suggesting a possible role in DNA binding. The RPA1 phosphoesterase (RPE) has a calcineurin-like phosphoesterase domain, and was not investigated individually. However, our results and those of Skowyra and MacNeill (2012) show that rpe is a non-essential gene.

To study the roles of RPAP1 and RPAP3 in DNA repair, $\Delta$ rpap1 (H1216) and $\Delta$ rpap3 (H1410) mutants were generated, both using trpA-marked deletion constructs (Figures 2 and 3, respectively). As with $\Delta$ rpal strain $\mathrm{H} 1217$, the $\Delta$ rpap1 mutant $\mathrm{H} 1216$ showed no increased sensitivity to UV irradiation or to MMC-induced DNA damage. However, the $\Delta$ rpap3 deletion mutant $\mathrm{H} 1410$ was hypersensitive to both types of DNA damage, and the level of sensitivity was similar to that exhibited by the $\Delta$ rpa3 mutant H1244.

We examined whether the absence of both RPA and RPAP results in a synergistic deficiency in DNA repair. Genomic deletions of the rpal and rpa3 operons were generated in strains H1246 and H1260, respectively, with only the latter being a $\operatorname{trp} A$-marked deletion (Figures 2 and 3, respectively); deletions of the rpa1 and rpa3 operons have previously been reported by Skowyra and MacNeill (2012). The $\Delta$ rpal operon mutant showed no increased sensitivity to UV irradiation or to MMC-induced DNA damage. However the $\triangle r p a 3$ operon deletion mutant was hypersensitive to both types of DNA damage, and the level of sensitivity was similar to that exhibited by the single $\Delta r p a 3$ and $\Delta$ rpap3 mutants H1244 and H1410, respectively (Figure 4). This result suggests that RPA3 and RPAP3 function in the same pathway(s) of DNA repair.

\section{REDUNDANCY BETWEEN RPA1 AND RPA3 OPERONS}

In order to test for redundancy between the two RPAs, an attempt was made to generate a double $\Delta$ rpal operon $\Delta$ rpa3 operon deletion. This involved constructing the strain $\mathrm{H} 1282$, which contained the pop-in of a $\operatorname{trp} A$-marked $\triangle r p a 3$ operon construct (pTA1207) in an unmarked $\Delta$ rpal operon background (H1246). An episomal plasmid (pTA1265), marked with pyrE2 and providing in trans expression of the rpal operon was used for complementation during the pop-out step (note that this episomal plasmid is lost during counter-selection with 5-FOA). Neither of the two pop-outs generated from this strain (H1390) yielded the desired $\Delta r p a 1$ operon 


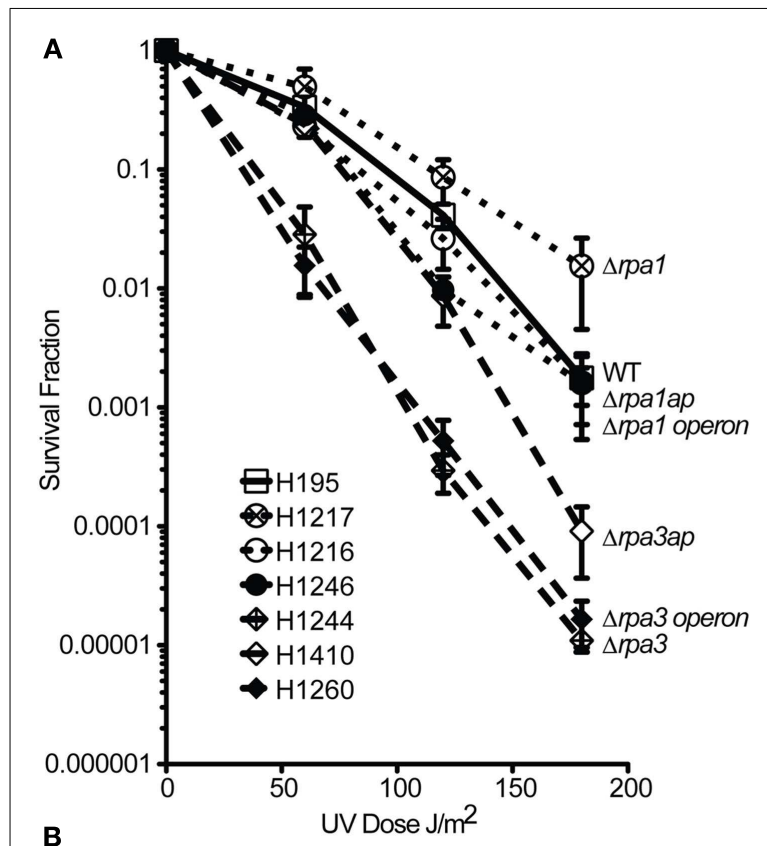

B

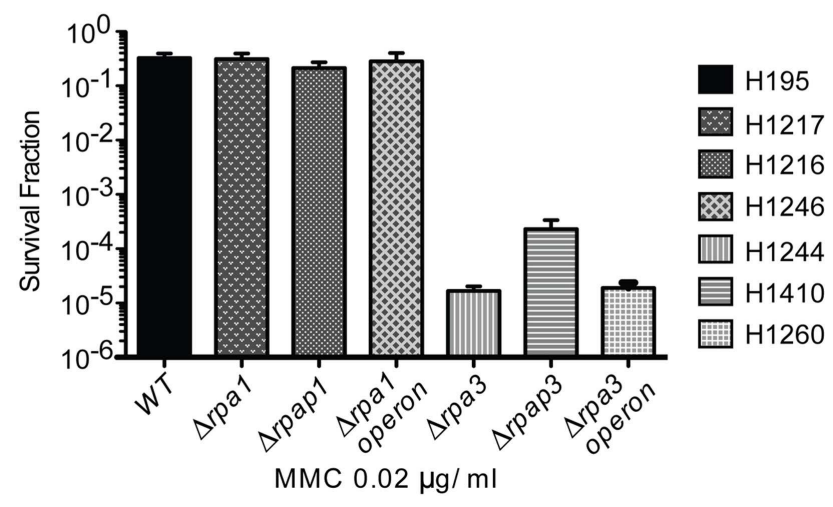

FIGURE 4 | (A) Wild-type (WT), rpa1, rpap1, rpa1 operon, rpa3, rрap3, rрa3 operon (H195, H1217, H1216, H1246, H1244, H1410, and H1260,

respectively), were plated out and exposed to ultraviolet (UV) radiation. The average and standard error (SE) of three experiments are shown. (B) The strains shown in (A) were plated out and exposed to mitomycin C (MMC). The average and SE of three experiments are shown.

$\Delta r p a 3$ operon mutant (see Figure A1 in Appendix). This indicates that the cell requires either RPA1 or RPA3 (and/or their respective RPAPs) for survival.

Next we attempted to generate $\Delta$ rpal $\Delta$ rpap3 and $\Delta r p a 3$ $\Delta$ rpap1 deletion mutants. This would test whether the RPAPs can complement each other, or whether they are instead specific for their respective RPAs. The trpA-marked $\triangle$ rpap3 construct (pTA1284) was used in an unmarked $\Delta$ rpal background (H1280), and the trpA-marked $\Delta r p a 3$ construct (pTA1207) was used in an unmarked $\Delta$ rpap1 background (H1281). In both cases two pop-outs were generated but none proved to be the desired deletions (see Figure 1 in Appendix). This suggests that the putative RPA:RPAP complex is dependent upon specific RPA:RPAP interactions for functionality.

\section{CONSTRUCTION OF PROTEIN OVEREXPRESSION STRAIN WITH C-TERMINAL TRUNCATION OF CDC48D}

In a previous publication (Allers et al., 2010), we constructed a strain of $H$. volcanii where the histidine-rich pitA gene is replaced by the ortholog from $N$. pharaonis. The latter protein lacks the histidine-rich linker region found in $H$. volcanii PitA and does not co-purify with His-tagged recombinant proteins. The absence of Hvo-PitA revealed an additional co-purifying protein, which we identified as Cdc48d (HVO_1907) and features a histidine-rich C-terminus (Figure 5A). We were unable to delete $c d c 48 d$, indicating that this gene is essential (Allers et al., 2010). The presence of this contaminating protein was problematic for purification of His-tagged RPA1 and RPAP1, due to similar molecular weights (Cdc48d, 53 kDa; RPA1, 46 kDa; RPAP1, $65 \mathrm{kDa})$.

All orthologs of Cdc48d from haloarchaea feature a histidinerich C-terminus, however Cdc48d from Haloarcula marismortui and $H$. salinarum have only three and four histidines, respectively, compared to six in H. volcanii (Figure 5A). Therefore, we replaced the $H$. volcanii $c d c 48 d$ gene in $H 1209$ (Allers et al., 2010) with orthologous genes from $H$. marismortui and $H$. salinarum, generating $H$. volcanii strains $\mathrm{H} 1405$ and $\mathrm{H} 1333$, respectively. Unfortunately these strains grew poorly and were not suitable for recombinant protein overexpression. Instead, we generated a truncated allele of $H$. volcanii $c d c 48 d$, encoding a Cdc48d protein lacking the histidine-rich C-terminus (Cdc48d-Ct; Figure 5A). The $c d c 48 d-C t$ allele was used to replace the H. salinarum $c d c 48 d$ gene in $H$. volcanii H1333, generating H1424 (Figures 5B,C). This strain exhibits normal cell growth and the Cdc48d-Ct protein no longer co-purifies with His-tagged recombinant proteins (Figure 5D). A number of minor histidine-rich contaminants are now apparent, which have been identified by mass spectrometry.

\section{DIRECT RPAP INTERACTION WITH RESPECTIVE RPA}

The genetic analysis of rpal and rpa3 and their respective rpap genes indicates not only that RPA3 and RPAP3 function in the same DNA repair pathway(s), but also that they function together as a specific RPA:RPAP complex. To establish whether this is achieved via a direct RPA:RPAP interaction, affinity pull-downs were employed (Allers et al., 2010). The rpal and rpa3 operons were cloned under control of the tryptophanase promoter in plasmid pTA963, where either the RPA or the RPAP was tagged with a hexahistidine tag.

Histidine-tagged RPA1 and RPA3 pulled down their respective RPAPs, and histidine-tagged RPAP1 and RPAP3 pulled down their respective RPAs (Figure 6). However, histidine-tagged RPA1 did not pull down RPAP3, and vice versa. This confirms that the RPAs interact specifically with their respective RPAPs, supporting our conclusions based on the failure to generate $\triangle r p a 1$ $\triangle$ rpap3 and $\triangle$ rpa3 $\triangle$ rpap1 deletion mutants. Neither RPA1 nor RPA3 pulled down RPA2, and histidine-tagged RPA2 did not pull down RPA1 or 3, or either of the RPAPs (data not shown). This supports the suggestion that the three RPAs of $H$. volcanii do not form a heterotrimer as observed in eukaryotes and $P$. furiosus, but instead form three separate ssDNA-binding factors. 


\section{A Cdc48d C-terminus}

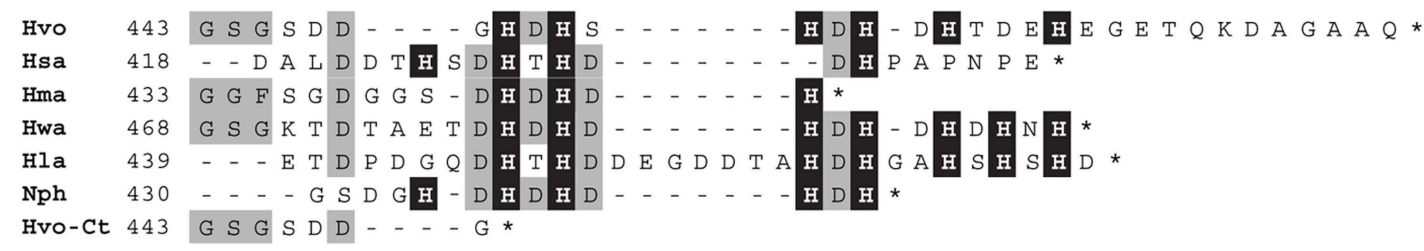

B

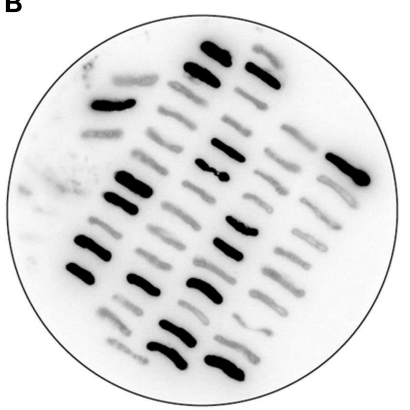

Hsa-cdc48d Probe

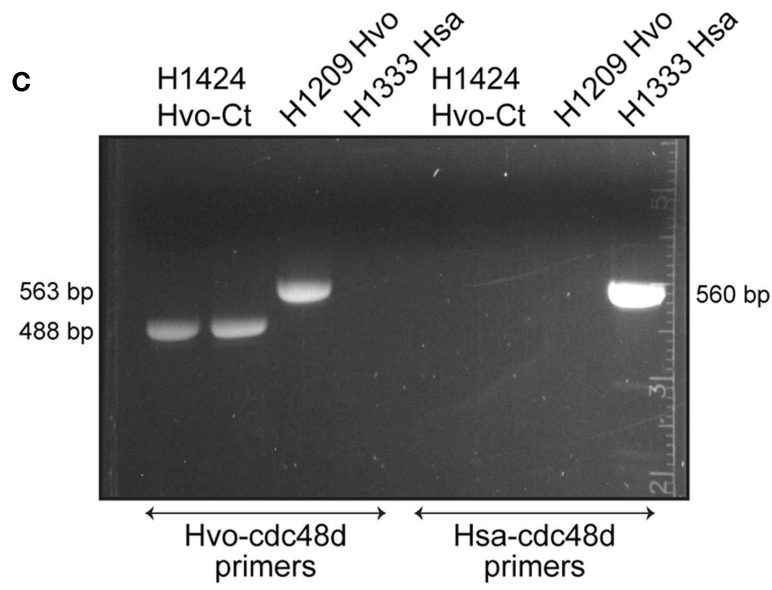

D

H1209<smiles>CC(=O)OCC(=O)O</smiles>
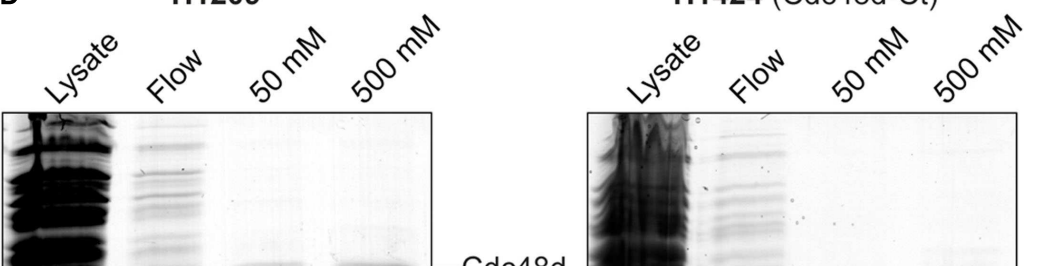

H1424 (Cdc48d-Ct)
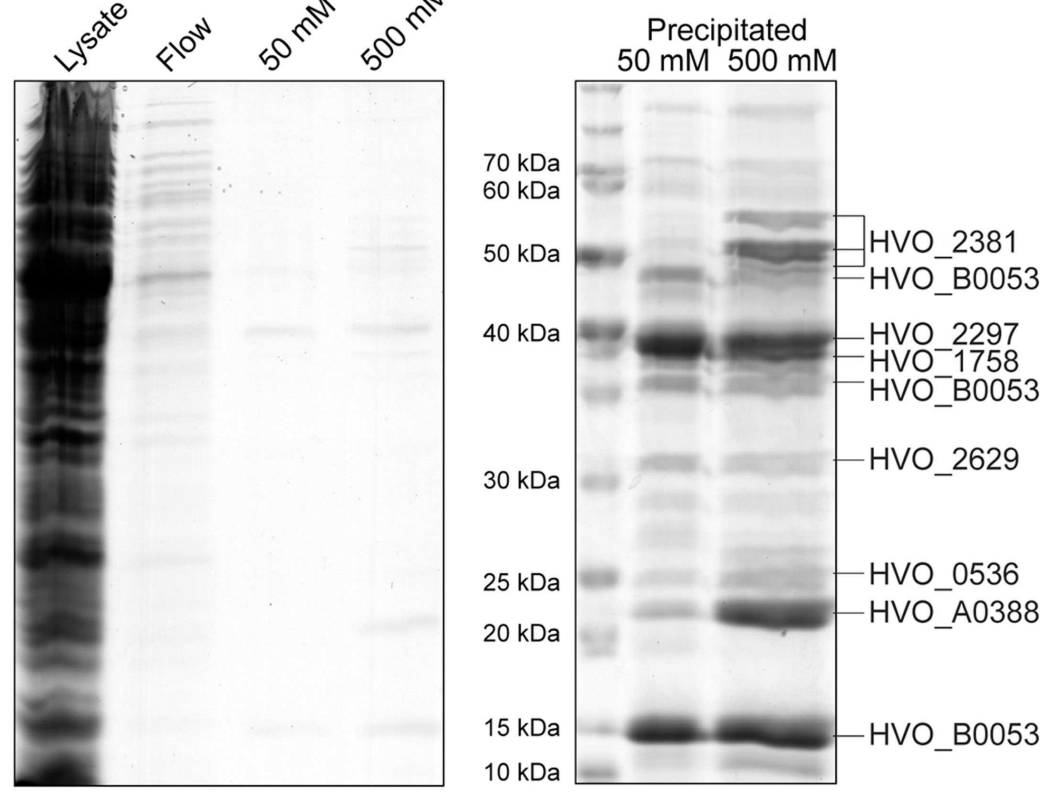

FIGURE 5 | (A) Protein sequence alignment of C-terminus of Cdc48d from selected species of haloarchaea (Hvo, H. volcanii; Hsa, Halobacterium salinarum; Hma, Haloarcula marismortui; Hwa, Haloquadratum walsbyi; Hla, Halorubrum lacusprofundi; Nph, N. pharaonis; Hvo-Ct, H. volcanii C-terminal truncation $\mathrm{Cdc} 48 \mathrm{~d}-\mathrm{Ct}$ ). Histidine residues are indicated by a black background. (B) Colony hybridization of 5-FOA-resistant clones of $H$. volcanii $\mathrm{H} 1333$, after pop-in/pop-out gene replacement with pTA1294. H. salinarum cdc48d sequences (Hsa-cdc48d) were used as a probe, clones failing to hybridize therefore carry the truncated $\mathrm{H}$. volcanii cdc48d-Ct allele present in pTA1294. (C) Verification of truncated cdc48d-Ct allele in $\mathrm{H} 1424$ by PCR (488 bp product), with primers specific to either $H$. volcanii or $H$. salinarum genes.
H1209 genomic DNA was used as a control for wild-type $H$. volcanii cdc48d (563 bp product), and $\mathrm{H} 1333$ was used as a control for $H$. salinarum cdc48d (560 bp product). (D) H. volcanii strains $\mathrm{H} 1209$ and $\mathrm{H} 1424$ containing empty vector pTA963 (Allers et al., 2010) were used in mock protein overexpression. Histidine-rich cellular proteins were purified from the soluble fraction (lysate) by affinity chromatography on a $\mathrm{Ni}^{2+}$ chelating column, samples were taken from the flow-through (flow) and bound proteins were eluted using 50 and $500 \mathrm{mM}$ imidazole. Precipitation using trichloroacetic acid and deoxycholate was used to enhance visualization and identification of the eluted proteins by mass spectrometry. Cdc48d (HVO_1907) eluted from cell extracts of H1209 but not from $\mathrm{H} 1424$ (cdc48d-Ct). 


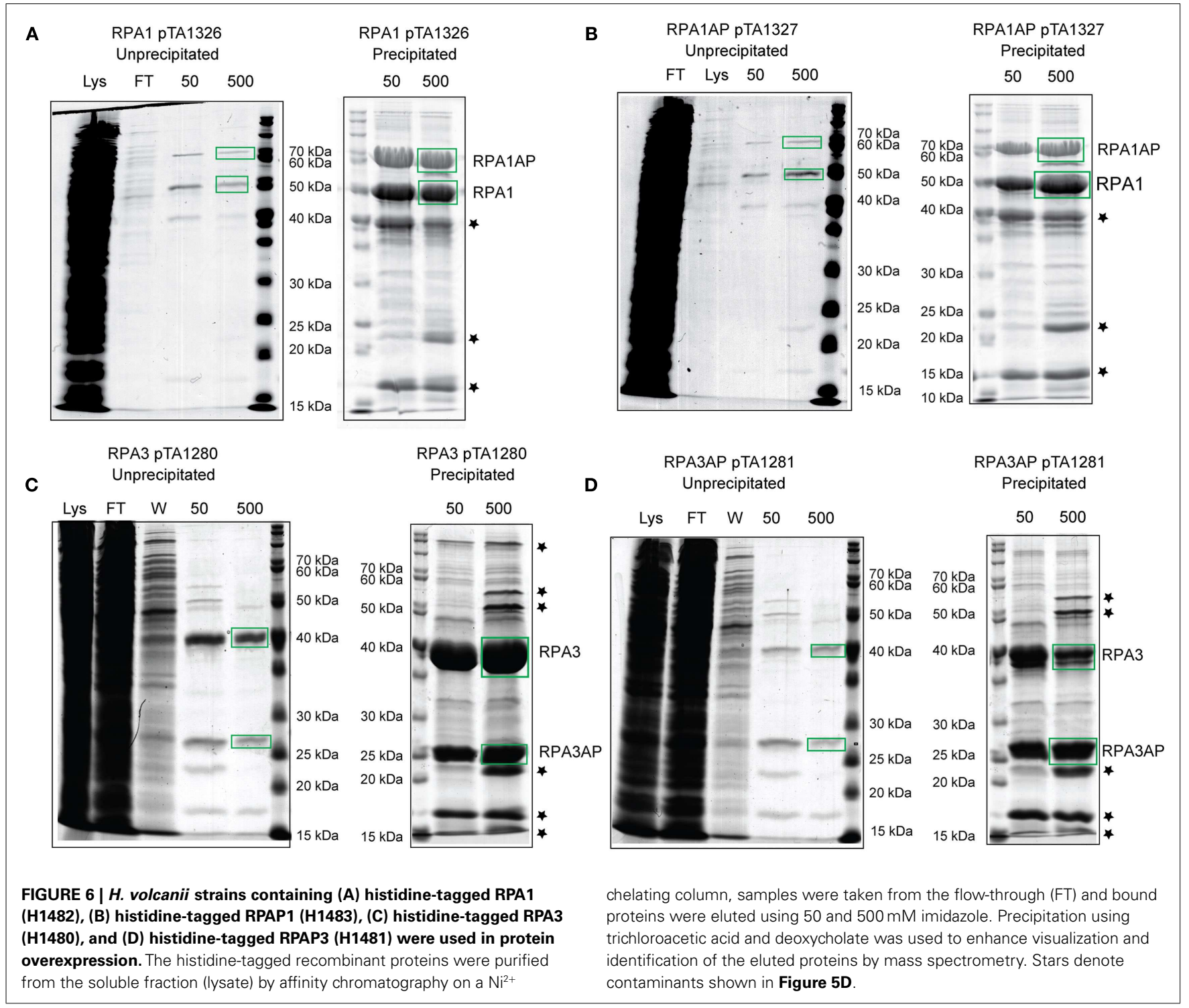

\section{DISCUSSION}

There is a unifying theme in archaea of a great variety in the number and type of proteins involved in DNA replication, and repair, whose counterparts in eukaryotes are much more uniform. This has been shown to be the case for RPA, where eukaryotes possess three subunits that all form unified clades in a phylogenetic analysis, but in archaea the number and structure of subunits varies widely. Some euryarchaea possess differing numbers of RPA subunits and some possess differing numbers of RPAs and RPAPs. Crenarchaea also possess varying numbers of SSB, however in both euryarchaea and crenarchaea none of the RPAs, RPAPs, or SSBs fall into unified clades. Again this is seen in the case of MCM, where eukaryotes possess six MCM subunits that each form unified clades, but in archaea there is a vast range in the number of MCM subunits, differing between individual species, and none of which fall into uniform clades (Chia et al., 2010). Characterizing the RPA-RPAP complexes of $H$. volcanii will shed light on how the RPAs and RPAPs function together in binding and stabilizing
ssDNA. This in turn will provide insight for other RPAs and RPAPs in archaea, but also offer reasoning behind the driving force of such non-uniform evolution of archaea.

The genetic and biochemical analysis presented here indicates the three RPAs of $H$. volcanii do not form a heterotrimeric complex as in P. furiosus and eukaryotes. Instead, RPA1 and RPA3 form complexes with their respective RPAPs. Unlike rpa2, both rpa1 and rpa3 genomic deletions were generated with relative ease, showing that the latter are not essential for cell survival and supporting the hypothesis that the three RPAs do not form a heterotrimeric complex.

The ease at which the rpal, rpap1, and rpal operon deletion mutants were made, coupled with a lack DNA damage sensitivity, signifies the rpal operon does not play a major role in DNA replication or repair. The moderate DNA damage sensitivity shown by the individual rpa3, rpap3, and the rpa3 operon mutants indicates that the efficient repair of UV and MMC-induced DNA damage requires the products of the rpa3 operon but not the 
rpal operon. However, it proved impossible to generate a double $\Delta$ rpal operon $\Delta r p a 3$ operon deletion, showing that cellular growth requires either RPA1 or RPA3.

Both single $\triangle r p a 3$ and $\Delta r p a p 3$ mutants showed a similar DNA damage sensitivity to each other, and to the rpa3 operon mutant, providing genetic evidence that RPA3 and RPAP3 act in the same DNA repair pathway. Furthermore, we were unable to generate $\Delta r p a 1 \Delta$ rpap3 and $\Delta r p a 3 \Delta r p a p 1$ deletion mutants, indicating that RPAP1 could not substitute for RPAP3 (and vice versa), and suggesting that the RPA3 interacts specifically with RPAP3 (and likewise for RPA1 and RPAP1). However it is unclear what role the associated proteins play, since the presence of an OB-fold does not necessarily indicate direct ssDNA binding. Instead, the RPAPs may provide a platform for protein:protein interactions. This is seen in eukaryotes, where the RPA $14 \mathrm{kDa}$ subunit possesses a single OB-fold, this subunit is essential for formation of the RPA heterotrimer by facilitating protein:protein interactions (Fanning et al., 2006).

The co-purification of histidine-tagged RPA1 and RPA3 with their respective untagged RPAPs (and vice versa) supports our hypothesis that $H$. volcanii RPA1 and RPA3 form complexes with their respective RPAPs. This observation, and the differing outcomes of rpa1, rpa2, and rpa3 deletions, indicates that the three RPAs of $H$. volcanii do not function as a heterotrimer. Similar

\section{REFERENCES}

Alberts, B. M., and Frey, L. (1970). T4 bacteriophage gene 32: a structural protein in the replication and recombination of DNA. Nature 227, 1313-1318.

Allers, T., Barak, S., Liddell, S., Wardell, K., and Mevarech, M. (2010). Improved strains and plasmid vectors for conditional overexpression of His-tagged proteins in Haloferax volcanii. Appl. Environ. Microbiol. 76, 1759-1769.

Allers, T., Ngo, H. P., Mevarech, M., and Lloyd, R. G. (2004). Development of additional selectable markers for the halophilic archaeon Haloferax volcanii based on the leuB and trpA genes. Appl. Environ. Microbiol. 70, 943-953.

Berthon, J., Cortez, D., and Forterre, P. (2008). Genomic context analysis in Archaea suggests previously unrecognized links between DNA replication and translation. Genome Biol. 9 , R71.

Bochkarev, A., and Bochkareva, E. (2004). From RPA to BRCA2: lessons from single-stranded DNA binding by the OB-fold. Curr. Opin. Struct. Biol. 14, 36-42.

Brill, S. J., and Stillman, B. (1991). Replication factor-A from Saccharomyces cerevisiae is encoded by three essential genes coordinately expressed at $\mathrm{S}$ phase. Genes Dev. 5, 1589-1600.

Chia, N., Cann, I., and Olsen, G. J. (2010). Evolution of
DNA replication protein complexes in eukaryotes and Archaea. PLoS ONE 5, el0866. doi:10.1371/journal.pone.0010866

Coverley, D., Kenny, M. K., Lane, D. P., and Wood, R. D. (1992). A role for the human single-stranded DNA binding protein HSSB/RPA in an early stage of nucleotide excision repair. Nucleic Acids Res. 20, 3873-3880.

Coverley, D., Kenny, M. K., Munn, M., Rupp, W. D., Lane, D. P., and Wood, R. D. (1991). Requirement for the replication protein SSB in human DNA excision repair. Nature 349, 538-541.

Cubeddu, L., and White, M. F. (2005). DNA damage detection by an archaeal single-stranded DNAbinding protein. J. Mol. Biol. 353, 507-516.

Delmas, S., Shunburne, L., Ngo, H. P., and Allers, T. (2009). Mre11Rad50 promotes rapid repair of DNA damage in the polyploid archaeon Haloferax volcanii by restraining homologous recombination. PLoS Genet. 5, e1000552. doi:10.1371/journal.pgen.1000552

Fanning, E., Klimovich, V., and Nager, A. R. (2006). A dynamic model for replication protein A (RPA) function in DNA processing pathways. Nucleic Acids Res. 34, 4126-4137.

Fousteri, M., and Mullenders, L. H. (2008). Transcription-coupled nucleotide excision repair in

results have been obtained in M. acetivorans, where the three RPAs are able to bind ssDNA individually, in addition to stimulating primer extension by M. acetivorans DNA polymerase BI in vitro. (Robbins et al., 2004).

This study has shown genetically and biochemically that RPAPs interact with RPAs, and that this interaction is RPA-specific. This is the first report investigating the function of the archaeal COG3390 RPA-associated proteins (RPAPs), thus providing an important insight of the structure and function of $H$. volcanii single-strand DNA-binding proteins.

\section{AUTHOR CONTRIBUTIONS}

Amy Stroud and Thorsten Allers wrote the paper; Amy Stroud and Thorsten Allers designed the experiments; Amy Stroud and Thorsten Allers performed the microbiological and biochemical experiments; Susan Liddell carried out the mass spectrometry; Amy Stroud, Susan Liddell, and Thorsten Allers analyzed the data.

\section{ACKNOWLEDGMENTS}

We are grateful to the BBSRC for a PhD studentship awarded to Amy Stroud and the Royal Society for a University Research Fellowship awarded to Thorsten Allers. We thank Kayleigh Wardell for help with strain construction, and Ed Bolt, Geoff Briggs, and Karen Bunting for their advice.

mammalian cells: molecular mechanisms and biological effects. Cell Res. 18, 73-84.

Guy, C. P., Haldenby, S., Brindley, A. Walsh, D. A., Briggs, G. S., Warren, M. J., Allers, T., and Bolt, E. L. (2006). Interactions of RadB, a DNA repair protein in Archaea, with DNA and ATP. J. Mol. Biol. 358, 46-56.

Hartman, A. L., Norais, C., Badger, J. H., Delmas, S., Haldenby, S., Madupu, R., Robinson, J., Khouri, H., Ren, Q., Lowe, T. M., Maupin-Furlow, J., Pohlschroder, M., Daniels, C., Pfeiffer, F., Allers, T., and Eisen, J. A. (2010). The complete genome sequence of Haloferax volcanii DS2, a model archaeon. PLoS ONE 5, e9605. doi:10.1371/journal.pone.0009605

Haseltine, C. A., and Kowalczykowski, S. C. (2002). A distinctive singlestrand DNA-binding protein from the archaeon Sulfolobus solfataricus. Mol. Microbiol. 43, 1505-1515.

Heyer, W. D., Rao, M. R., Erdile, L. F., Kelly, T. J., and Kolodner, R. D. (1990). An essential Saccharomyces cerevisiae single-stranded DNA binding protein is homologous to the large subunit of human RP-A. EMBO J. 9, 2321-2329.

Kenny, M. K., Lee, S. H., and Hurwitz, J. (1989). Multiple functions of human single-stranded-DNA binding protein in simian virus 40 DNA replication: single-strand stabilization and stimulation of DNA polymerases alpha and delta. Proc. Natl. Acad. Sci. U.S.A. 86, 9757-9761.

Kerr, I. D., Wadsworth, R. I., Cubeddu, L., Blankenfeldt, W., Naismith, J. H., and White, M. F. (2003). Insights into ssDNA recognition by the $\mathrm{OB}$ fold from a structural and thermodynamic study of Sulfolobus SSB protein. EMBO J. 22, 2561-2570.

Kim, C., Snyder, R. O., and Wold, M. S. (1992). Binding properties of replication protein A from human and yeast cells. Mol. Cell. Biol. 12, 3050-3059.

Komori, K., and Ishino, Y. (2001). Replication protein A in Pyrococcus furiosus is involved in homologous DNA recombination. J. Biol. Chem. 276, 25654-25660.

Lestini, R., Duan, Z., and Allers, T. (2010). The archaeal Xpf/Mus81/FANCM homolog Hef and the Holliday junction resolvase $\mathrm{Hjc}$ define alternative pathways that are essential for cell viability in Haloferax volcanii. DNA Repair (Amst.) 9, 994-1002.

Lin, Y., Lin, L. J., Sriratana, P., Coleman, K., Ha, T., Spies, M., and Cann, I. K. (2008). Engineering of functional replication protein a homologs based on insights into the evolution of oligonucleotide/oligosaccharidebinding folds. J. Bacteriol. 190, 5766-5780.

Lu, D., and Keck, J. L. (2008). Structural basis of Escherichia coli singlestranded DNA-binding protein 
stimulation of exonuclease I. Proc. Natl. Acad. Sci. U.S.A. 105, 9169-9174.

Lu, D., Windsor, M. A., Gellman, S. H., and Keck, J. L. (2009). Peptide inhibitors identify roles for SSB C-terminal residues in $\mathrm{SSB} /$ exonuclease I complex formation. Biochemistry 48, 6764-6771.

Moore, S. P., Erdile, L., Kelly, T., and Fishel, R. (1991). The human homologous pairing protein HPP-1 is specifically stimulated by the cognate single-stranded binding protein hRP-A. Proc. Natl. Acad. Sci. U.S.A. 88, 9067-9071.

Mullakhanbhai, M. F., and Larsen, H. (1975). Halobacterium volcanii spec. nov., a Dead Sea halobacterium with a moderate salt requirement. Arch. Microbiol. 104, 207-214.

Robbins, J. B., McKinney, M. C., Guzman, C. E., Sriratana, B., FitzGibbon, S., Ha, T., and Cann, I. K. (2005). The euryarchaeota, nature's medium for engineering of singlestranded DNA-binding proteins. J. Biol. Chem. 280, 15325-15339.
Robbins, J. B., Murphy, M. C., White, B. A., Mackie, R. I., Ha, T., and Cann, I. K. (2004). Functional analysis of multiple single-stranded DNA-binding proteins from Methanosarcina acetivorans and their effects on DNA synthesis by DNA polymerase BI. J. Biol. Chem. 279, 6315-6326.

Rolfsmeier, M. L., and Haseltine, C. A. (2010). The single-stranded DNA binding protein of Sulfolobus solfataricus acts in the presynaptic step of homologous recombination. J. Mol. Biol. 397, 31-45.

Rouillon, C., and White, M. F. (2011). The evolution and mechanisms of nucleotide excision repair proteins. Res. Microbiol. 162, 19-26.

Sambrook, J., and Russell, D. W. (2001). Molecular Cloning: A Laboratory Manual. Cold Spring Harbor, NY: Cold Spring Harbor Laboratory Press.

Skowyra, A., and MacNeill, S. A. (2012). Identification of essential and non-essential single-stranded DNA-binding proteins in a model archaeal organism. Nucleic Acids Res. 40, 1077-1090.

Tomasz, M., Lipman, R., Chowdary D., Pawlak, J., Verdine, G. L. and Nakanishi, K. (1987). Isolation and structure of a covalent cross-link adduct between mitomycin C and DNA. Science 235, 1204-1208.

Wobbe, C. R., Weissbach, L., Borowiec, J. A., Dean, F. B., Murakami, Y., Bullock, P., and Hurwitz, J. (1987). Replication of simian virus 40 origin-containing DNA in vitro with purified proteins. Proc. Natl. Acad. Sci. U.S.A. 84, 1834-1838.

Wold, M. S. (1997). Replication protein A: a heterotrimeric, single-stranded DNA-binding protein required for eukaryotic DNA metabolism. Annu. Rev. Biochem. 66, 61-92.

Wold, M. S., Weinberg, D. H., Virshup, D. M., Li, J. J., and Kelly, T. J. (1989). Identification of cellular proteins required for simian virus 40 DNA replication. J. Biol. Chem. 264, 2801-2809.
Conflict of Interest Statement: The authors declare that the research was conducted in the absence of any commercial or financial relationships that could be construed as a potential conflict of interest.

Received: 15 March 2012; accepted: 31 May 2012; published online: 18 June 2012.

Citation: Stroud A, Liddell S and Allers $T$ (2012) Genetic and biochemical identification of a novel single-stranded DNA-binding complex in Haloferax volcanii. Front. Microbio. 3:224. doi: 10.3389/fmicb.2012.00224

This article was submitted to Frontiers in Evolutionary and Genomic Microbiology, a specialty of Frontiers in Microbiology. Copyright (๑) 2012 Stroud, Liddell and Allers. This is an open-access article distributed under the terms of the Creative Commons Attribution Non Commercial License, which permits non-commercial use, distribution, and reproduction in other forums, provided the original authors and source are credited. 


\section{APPENDIX}

Table A1 | Identification of proteins present in cellular soluble fraction after purification by affinity chromatography on a $\mathrm{Ni}^{2+}$ chelating column.

\begin{tabular}{lllllllc}
\hline Prot accession & Protein name & HVO_\# & $\begin{array}{l}\text { Predicted } \\
\text { MW }\end{array}$ & Observed MW & $\begin{array}{l}\text { MASCOT } \\
\text { score }\end{array}$ & $\begin{array}{l}\text { Number } \\
\text { of peptides }\end{array}$ & $\begin{array}{l}\text { \% coverage } \\
\text { Peptide } \\
\text { sequences }\end{array}$ \\
\hline gi[292655491] & RPAP1 & 1337 & 64,829 & 57,781 & 671 & 12 & 18 \\
gi[292655492] & RPA1 & 1338 & 45,954 & 36,960 & 940 & 15 & 40 \\
gi[292655491] & RPAP1 & 1337 & 64,829 & 62,780 & 578 & 10 & 21 \\
gi[292655492] & RPA1 & 1338 & 45,954 & 45,686 & 808 & 15 & 40 \\
gi[292654471] & RPAP3 & 0291 & 21,979 & 15,074 & 435 & 10 & 53 \\
gi[292654471] & RPAP3 & 0291 & 21,979 & 16,217 & 484 & 10 & 12 \\
gi[292654472] & RPA3 & 0292 & 34,562 & 28,262 & 796 & 13 & 7 \\
gi[292654472] & RPA3 & 0292 & 34,562 & 31,741 & 735 & 13 & 43 \\
gi[292656508] & Hypothetical protein & 2381 & 52,319 & $55,300 / 50,200$ & 240 & 5 & 48 \\
gi[292493992] & Hypothetical protein & B0053 & 13,897 & $4,73,600$ & 259 & 4 & 11 \\
gi[292656425] & Deoxyhypusine synthase & 2297 & 38,616 & 39,500 & 451 & 7 & 33 \\
gi[292655899] & Thioredoxin reductase & 1758 & 36,505 & 38,000 & 312 & 6 & 25 \\
gi[292493992] & Hypothetical protein & B0053 & 13,897 & 36,300 & 208 & 6 & 21 \\
gi[292656748] & Htr-like protein & 2629 & 30,266 & 31,700 & 93 & 4 & 5 \\
gi[292654704] & Ferritin & 0536 & 19,892 & 24,900 & 66 & 1 & 4 \\
gi[292653937] & Transcriptional regulator & A0388 & 20,201 & 22,300 & 586 & 15 & 17 \\
gi[292493992] & Hypothetical protein & B0053 & 13,897 & 13,500 & 170 & 3 & 6 \\
\hline
\end{tabular}

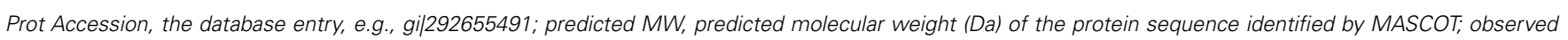

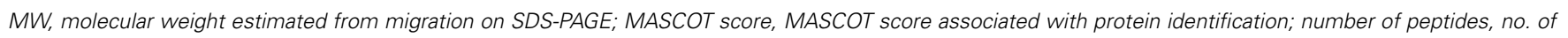

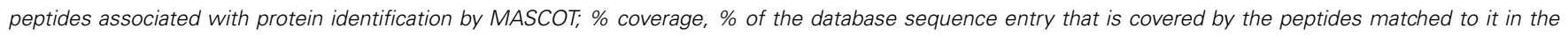
MASCOT data. Peptide sequences, the number of distinct peptide sequences associated with the protein identified by MASCOT. 

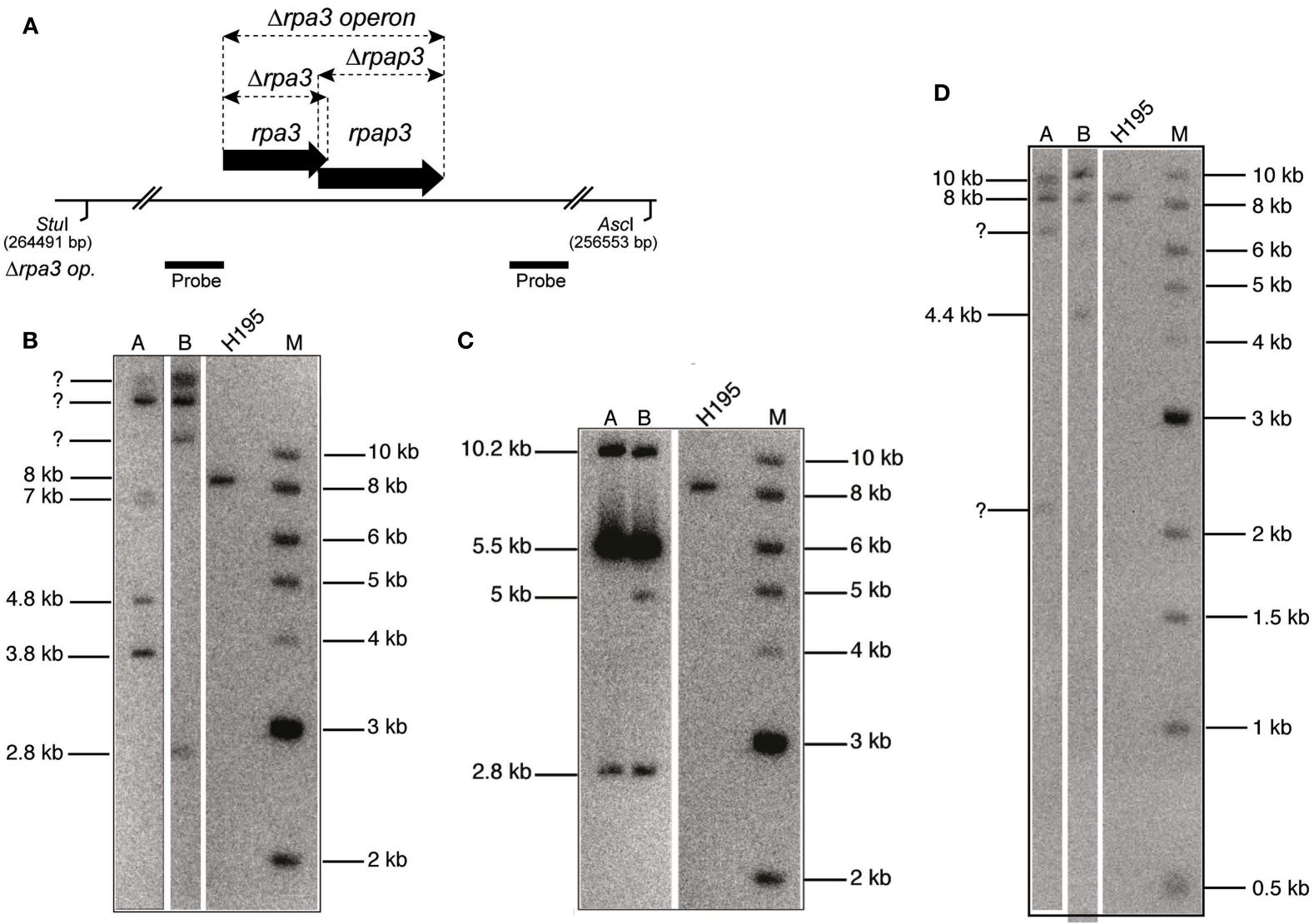

FIGURE A1 | (A) Map of rpa3 operon indicating location of $\Delta r p a 3, \Delta r p a p 3$, and $\Delta$ rpa3 operon deletions, as well as the Ascl and Stul sites and the probe used to verify the deletions. The size of this fragment in the wild-type $(\mathrm{H} 195)$ is $8 \mathrm{~kb}$. (B) Southern blot of genomic DNA cut with Ascl and Stul, and probed with flanking regions of rpa3 operon (rpa3 op.), as shown in (A), indicates failure to generate $\Delta$ rpa $1 \Delta$ rpap3 mutant as bands of the expected size for deletion are not seen (3.4 and $4.4 \mathrm{~kb}$ ). (C) Southern blot of genomic DNA cut with Ascl and Stul, and probed with flanking regions of rpa3 op., as shown in (A), indicates failure to generate $\Delta$ rpap $1 \Delta$ rpa3 mutant as bands of the expected size for deletion are not seen (2.8 and $5 \mathrm{~kb}$ ). (D) Southern blot of genomic DNA cut with $\mathrm{AsCl}$ and Stul, and probed with flanking regions of rpa3 op., as shown in (A) indicates failure to generate $\Delta$ rpa 1 operon $\Delta r p a 3$ operon mutant as bands of the expected size for deletion are not seen (2.8 and $3.4 \mathrm{~kb}$ ). 